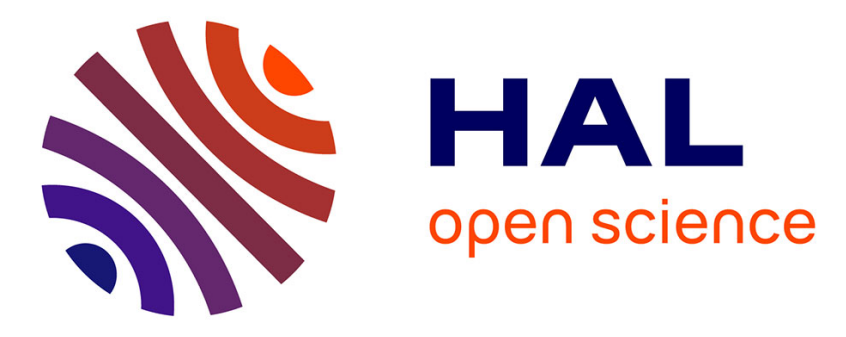

\title{
Study and Development of Multilayer Needle-type Enzyme-based Glucose Microsensors
}

Robert Stemberg, Marie-Bernadette Barrau, Laurent Gangiotti, Daniel R. Thevenot, Dilbir S. Bindra, George S. Wilson, Gilberto Velho, Philippe Froguel, Gérard Reach

\section{To cite this version:}

Robert Stemberg, Marie-Bernadette Barrau, Laurent Gangiotti, Daniel R. Thevenot, Dilbir S. Bindra, et al.. Study and Development of Multilayer Needle-type Enzyme-based Glucose Microsensors. Biosensors, 1988, 4, pp.27 - 40. hal-01179712

\section{HAL Id: hal-01179712 \\ https://hal.science/hal-01179712}

Submitted on 24 Jul 2015

HAL is a multi-disciplinary open access archive for the deposit and dissemination of scientific research documents, whether they are published or not. The documents may come from teaching and research institutions in France or abroad, or from public or private research centers.
L'archive ouverte pluridisciplinaire HAL, est destinée au dépôt et à la diffusion de documents scientifiques de niveau recherche, publiés ou non, émanant des établissements d'enseignement et de recherche français ou étrangers, des laboratoires publics ou privés. 


\title{
Study and Development of Multilayer Needle-type Enzyme- based Glucose Microsensors
}

\author{
Robert Sternberg, Marie-Bernadette Barrau, \\ Laurent Gangiotti, Daniel R. Thévenot*
}

Laboratoire de Bioélectrochimie et Analyse du Milieu (LABAM), U.F.R. de Sciences et de Technologie, Université Paris-Val de Marne, Avenue du Générale de Gaulle, 94010 Créteil, Cedex, France

\section{Dilbir S. Bindra, George S. Wilson}

University of Kansas, Department of Chemistry, Lawrence, Kansas 66045, USA

\section{Gilberto Velho, Philippe Froguel \& Gérard Reach}

Hotel-Dieu Hospital, Diabetology Department, 1 Place du Parvis de Notre Dame, 75004 Paris, France

(Received 20 March 1988; revised version received and accepted 6 May 1988)

\section{ABSTRACT}

Glucose oxidase (GOD) was covalently coupled to a cellulose acetate $(C A)$ layer, using bovine serum albumin (BSA) and parabenzoquinone ( $P B Q$ ) linkages. Prior to GOD coupling this $C A$ layer was deposited on the platinum tip of a needle-type sensor and covered with an outer layer of polyurethane (PU). Such microsensors were found to be active, their GOD load reaching 1.6 to $3.0 \mu \mathrm{g} \mathrm{mm}^{-2}$ and their glucose response reaching 1 to $3 \mu \mathrm{A} \mathrm{M} \mathrm{Mm}^{-1} \mathrm{~mm}^{-2}$, even when the upper limit of their linear range reached $10-30 \mathrm{mM}$. Due to the multilayer structure and composition of these microsensors, small anions such as ascorbate were partially discriminated from neutral molecules such as hydrogen peroxide. When implanted subcutaneously in anaesthetized rats, sensor responses correlated correctly with blood glucose concentration but presented sensitivity coefficients significantly different to those determined in vitro: a 2 point calibration procedure was found necessary for in vivo experiments.

Key words: Glucose, microsensor, needle, subcutaneous, cellulose acetate, polyurethane, glucose oxidase, parabenzoquinone.

*To whom all correspondence should be sent.

Biosensors 0265-928X/88/\$03.50 (C) 1988 Elsevier Science Publishers Ltd, England. Printed in Great Britain 


\section{INTRODUCTION}

A critical element in enzyme-based sensor development is the enzyme membrane, which has to sustain and protect the enzyme in the vicinity of the electrochemical detector.

Among the various methods that we have studied for preparation of glucose oxidase (GOD) membranes, namely entrapment in cellulose acetate (CA) membranes (Tallagrand et al., 1988) and covalent coupling to collagen by the acyl-azide procedure (Thévenot et al., 1978, 1979, 1982; Sternberg et al., 1980), coupling to CA by carbonyldiimidazole (CDI) (Cherifi, 1986), or by bovine serum albumin (BSA) parabenzoquinone (PBQ) linkage (Sternberg et al., in press), we have found that the latter method gives the most suitable membrane for implantable glucose sensor development. Indeed such CA-BSA-PBQ-GOD membranes are thin (5$25 \mu \mathrm{m})$, stable at $37^{\circ} \mathrm{C}$ and very active, giving rise to a $4-10 \mathrm{~mA} \mathrm{M}^{-1} \mathrm{~cm}^{-2}$ glucose response (Sternberg et al., in press). Thus we have adapted the preparation procedure of such membranes to a needle-type geometry using a thin CA coating on platinum. This report presents preliminary results obtained with such Pt-CA-BSA-PBQ-GOD needle-type microsensors possessing additionally an outer layer of polyurethane (PU) which serves to increase the upper limit of linear range of glucose calibration curves to at least $15 \mathrm{~mm}$ (Shichiri et al., 1982, 1987), a requirement for in vivo blood glucose monitoring (Thévenot, 1982; Shichiri \& Kawamori, 1983; Reach et al., 1986; Velho et al., 1987).

\section{MATERIALS AND METHODS}

\section{Equipment}

Amperometry was performed using a Solea-Tacussel (Villeurbanne, France) PRGE polarograph or PRGE-DEL amperometric unit. Currenttime curves were recorded on a Linseis L65143-channel recorder (Selb, FRG). Data were stored and processed with an Apple IIe micro-computer.

A potential of $+0.650 \mathrm{~V}$ versus $\mathrm{Ag} / \mathrm{AgCl}$ was applied to the working electrode during all measurements. This potential enables the anodic oxidation of hydrogen peroxide produced by the enzymatic reaction of glucose with oxygen:

$$
\text { Glucose }+\mathrm{O}_{2}+\mathrm{H}_{2} \mathrm{O} \stackrel{\text { GOD }}{\longrightarrow} \text { Gluconate }+\mathrm{H}_{2} \mathrm{O}_{2}
$$

In vitro experiments were performed with a $5 \mathrm{ml}$ thermostated cell containing the needle-type glucose sensor and an external $\mathrm{Ag} / \mathrm{AgCl}$ reference electrode. The structure of the sensor is shown in Fig. 1. It is a two-electrode 


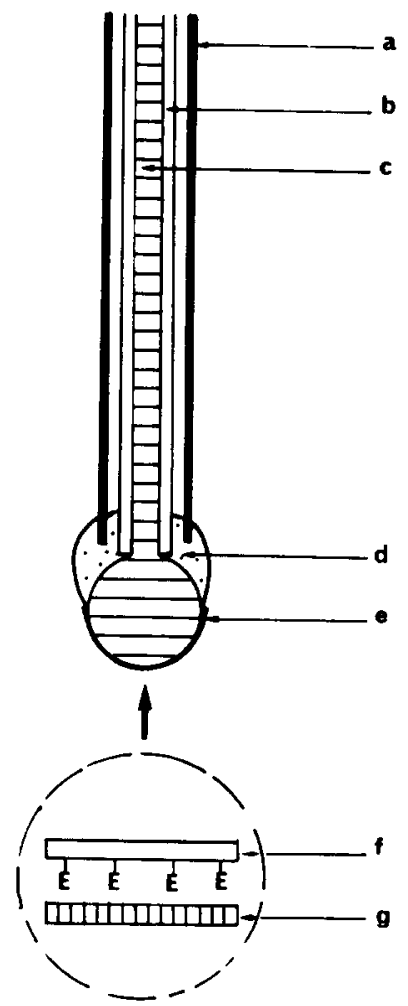

Fig. 1. Schematic diagram of the needle-type sensor. (a) $\mathrm{Ag} / \mathrm{AgCl}$ auxiliary and pseudoreference electrode, (b) polyethylene catheter, (c) platinum wire and microsphere working electrode, (d) epoxy glue, (e) multilayer enzyme membrane, (f) CA-BSA-PBQ-GOD and (g) PU mono- or multilayer.

sensor with a platinum working electrode and a silver/silver chloride auxiliary/pseudo-reference electrode. The temperature of buffer and standard solutions was maintained at $37^{\circ} \mathrm{C}$ with a Haake F E2 thermostated bath (Karlsruhe, FRG) and all solutions were air-saturated at that temperature.

\section{Reagents}

Phosphate buffered saline solution (PBS), $\mathrm{pH} 7 \cdot 4$, was prepared from $0.15 \mathrm{M}$ disodium phosphate and $0.15 \mathrm{M}$ sodium chloride brought to the appropriate $\mathrm{pH}$ with $1 \mathrm{M}$ hydrochloric acid. Borate buffer solutions were prepared with $0 \cdot 1 \mathrm{M}$ orthoboric acid adjusted to $\mathrm{pH} 9$ with $1 \mathrm{M}$ sodium hydroxide. All buffers used were filtered through a $0.45 \mu \mathrm{m}$ filter and stored at $4^{\circ} \mathrm{C}$.

Glucose oxidase (GOD, EC 1.1.3.4) from Aspergillus niger (grade II, $215 \mathrm{U} / \mathrm{mg}$ ) was obtained from Boehringer (Mannheim, FRG). Bovine 
serum albumin (BSA) (fraction V) was obtained from Sigma Chemical Co. (St Louis, USA).

Sodium periodate and sodium cyanoborohydride were obtained from Aldrich Jansen Chimica (Strasbourg, France). Parabenzoquinone (PBQ) was obtained from Merck (Darmstadt, FRG). Cellulose diacetate (CA), acetone, ethanol, dimethylformamide (DMF), tetrahydrofuran (THF) and trichloroethylene were obtained from Prolabo (Normapur, analytical reagents, Paris, France). Polyurethane (PU) was generously provided by Enka AG (Research Institute, Obernburg, FRG). Solutions of $10^{-1} \mathrm{M}$ glucose were allowed to mutarotate at room temperature at least $3 \mathrm{~h}$ before use and were stored at $-20^{\circ} \mathrm{C}$. Solutions of $10 \mathrm{mM}$ hydrogen peroxide were stored at $4^{\circ} \mathrm{C}$. Sephadex G25 was obtained from Pharmacia (Uppsala, Sweden).

Platinum wire $(0.20 \mathrm{~mm}$ in diameter $)$ was obtained from Comptoir des métaux précieux (Paris, France). Polyethylene catheter $(0.30 \mathrm{~mm}$ i.d.) was obtained from Biotrol Pharma (Paris, France). A hypodermic needle (23 ga., 1.24 mm o.d.) was, at the authors' request, electrochemically plated with silver or gold (Usiflame, Saint Gratien, France) and was used in the construction of the needle sensor (see Fig. 1).

\section{Working electrode preparation}

The tip of a $\mathrm{Pt}$ wire $\left(10 \mathrm{~cm}\right.$ in length) was heated at $c .2450^{\circ} \mathrm{C}$ with a small oxygen-butane blow-lamp to form a small sphere with a surface area of $0 \cdot 9-2 \cdot 3 \mathrm{~mm}^{2}$ as determined by micrometer. The platinum wire was then sealed into a polyethylene catheter with epoxy glue and introduced into a hypodermic needle. The platinum ball was held on the needle and half covered with epoxy. The working electrode thus prepared was placed on a rotary support at $13 \mathrm{rpm}$ for $48 \mathrm{~h}$ to allow epoxy hardening. After cleaning the tip of the platinum microsphere with trichloroethylene, the sensor was dipped into an ultrasonic bath of distilled water for $5 \mathrm{~min}$ to eliminate any organic deposits.

The method of enzyme layer preparation consisted of covalent coupling between the activated enzyme and an activated cellulose acetate layer in 5 successive steps as indicated below.

(1) CA layer deposition. The platinum microsphere was dipped into a cellulose acetate solution $(0.11 \mathrm{~g} \mathrm{CA}$ in $2 \mathrm{ml}$ acetone and $2 \mathrm{ml}$ ethanol) and was dried at $21^{\circ} \mathrm{C}$ for $0.5 \mathrm{~h}$ to form a solid CA layer.

(2) CA layer activation. The CA layer of the sensor was oxidized in a $0 \cdot 1 \mathrm{M}$ sodium periodate solution for $2 \mathrm{~h}$ at $21^{\circ} \mathrm{C}$ and washed in distilled water for $5 \mathrm{~min}$. Then the needle was immersed in a $10 \mathrm{mg} / \mathrm{ml} \mathrm{BSA}$ solution in $\mathrm{pH} 9$ 
borate buffer for $18 \mathrm{~h}$ at $4^{\circ} \mathrm{C}$. The Schiff base thus formed was reduced with a $64 \mathrm{~mm}$ sodium cyanoborohydride solution for $2 \mathrm{~h}$ at $21^{\circ} \mathrm{C}$.

(3) GOD activation. A $0.6 \mathrm{ml}$ mixture of $45 \mathrm{mg} \mathrm{m}^{-1} \mathrm{GOD}$ in $\mathrm{pH} 7.4 \mathrm{PBS}$ and $20 \mathrm{mM}$ PBQ in ethanol was incubated at $37^{\circ} \mathrm{C}$ for $0.5 \mathrm{~h}$ and then filtered through a $1.5 \mathrm{~cm}$ o.d., $20 \mathrm{~cm}$ long, Sephadex G25 column $(20 \mathrm{ml}$ $\mathrm{h}^{-1}$ flow rate) in order to eliminate the PBQ excess (Ternynck \& Avrameas, 1976). The GOD-PBQ conjugate was collected in the first $1-1.5 \mathrm{ml}$ of effluent, adjusted to $\mathrm{pH} 8-9$ with $1 \mathrm{M}$ sodium carbonate solution and used for enzyme coupling.

(4) GOD coupling reaction. The CA-BSA layer of the sensor was dipped into the activated GOD-PBQ solution. After $48 \mathrm{~h}$ at $21^{\circ} \mathrm{C}$ the needle was washed with distilled water for $5 \mathrm{~min}$ and stored at room temperature in a dry state.

(5) PU layer deposition. Protocol 1: The previously described CA-BSAPBQ-GOD covered platinum sphere was dipped into a $2-4 \%$ PU solution in a THF-DMF mixture (98\% THF and $2 \%$ DMF) and dried at $21^{\circ} \mathrm{C}$ for $1 \mathrm{~h}$. Protocol 2: The enzyme layer preparation involved the five previous steps but the needle was dried at $21^{\circ} \mathrm{C}$ for $24 \mathrm{~h}$ before and after PU layer deposition.

\section{Pseudo-reference electrode preparation}

The pseudo-reference electrode was prepared by anodization of the silver coating at a potential of $+0.650 \mathrm{~V}$ versus $\mathrm{Ag} / \mathrm{AgCl}$ for $30-45 \mathrm{~s}$ in $\mathrm{KCl}$ saturated solution with a current density of $7.5 \mathrm{~mA} \mathrm{~cm}^{-2}$. The stability of the $\mathrm{Ag} / \mathrm{AgCl}$ coated needle auxiliary/pseudo-reference electrode was monitored during experiments with an external $\mathrm{Ag} / \mathrm{AgCl}$, saturated $\mathrm{KCl}$ reference electrode.

The needle-type microsensor was $5-6 \mathrm{~cm}$ in length with $1.24 \mathrm{~mm}$ o.d.

\section{Radiolabelled GOD}

Preparation of ${ }^{125} \mathrm{I}-\mathrm{GOD}$ and its use for monitoring the amount of GOD immobilized on the CA-BSA-PBQ-GOD membrane has been previously described (Sternberg et al., in press). It was applied without modification for needle-type microsensors.

\section{In vivo studies}

Overnight-fasted male Wistar rats $(250-300 \mathrm{~g}$ body weight, Janvier, Saint Berthevi, France) were anaesthetized with pentobarbital $\left(50 \mathrm{mg} \mathrm{kg}^{-1}\right.$ intraperitoneally, Clin Midy, Saint Jean de la Ruelle, France) and polyethylene 
(Bitrol 3, Biotrol, France) and silicone (Silastic 602-135, Dow Corning, Midland, Michigan, USA) catheters were inserted respectively into the left jugular vein and homolateral carotid artery, for glucose or insulin injection, and for blood sampling for the determination of blood glucose concentration. After its in vitro characterization, the sensor was implanted in the subcutaneous tissue, through a small cervical incision. Animals were kept spontaneously breathing under a flow of carbogen $\left(\mathrm{O}_{2}-\mathrm{CO}_{2}, 95: 5\right)$ and warmed under a lamp, to prevent peripheral vasoconstriction.

At least one hour after surgery, when blood glucose and sensor output were stable, $1 \mathrm{U}$ insulin (Endopancrine U40, Organon, Saint Denis, France) was injected through the jugular catheter. When insulin-induced fall in blood glucose reached a trough, a continuous intravenous glucose infusion (20 to $60 \mathrm{mg} \mathrm{kg}^{-1} \mathrm{~min}^{-1}$ ) (infusion pump, Infu 362, Datex, Uhwiesen, Switzerland) was initiated to bring the blood glucose (and the subcutaneous glucose) to hyperglycaemic levels. Blood samples $(0.3 \mathrm{ml})$ were serially drawn through the carotid catheter, at 5 min intervals from -10 to $50 \mathrm{~min}$ for the insulin induced hypoglycaemia, and from 0 to $40 \mathrm{~min}$ for the glucose infusion. Samples were immediately centrifuged and plasma glucose concentration was determined with a glucose analyzer (Beckman, Fullerton, California, USA).

\section{RESULTS AND DISCUSSION}

\section{Sensor preparation}

All experiments presented in this report were performed using covalent coupling of GOD on BSA-activated CA layers. This method was derived from a procedure described by Ternynck and Avrameas (1976) using PBQ to couple amino groups of proteins. As CA membranes or layers usually possess low levels of accessible hydroxyl groups for covalent enzyme coupling, we increased the number of reacting groups by first covalently coupling BSA to CA (Sternberg et al., in press).

As such sensors yielded an upper limit of linear range of their calibration curves, reaching only 2-3 mM, it was necessary to cover the GOD layer with an outer layer restricting the diffusion of glucose to the reaction layer. This PU deposition procedure was extensively studied using either a single layer or multilayer coating procedure.

\section{Polyurethane outer layer deposition}

Using the same PU polymer preparation, we varied its concentration between 2 and $4 \%$, with the THF-DMF solvent mixture depositing one 


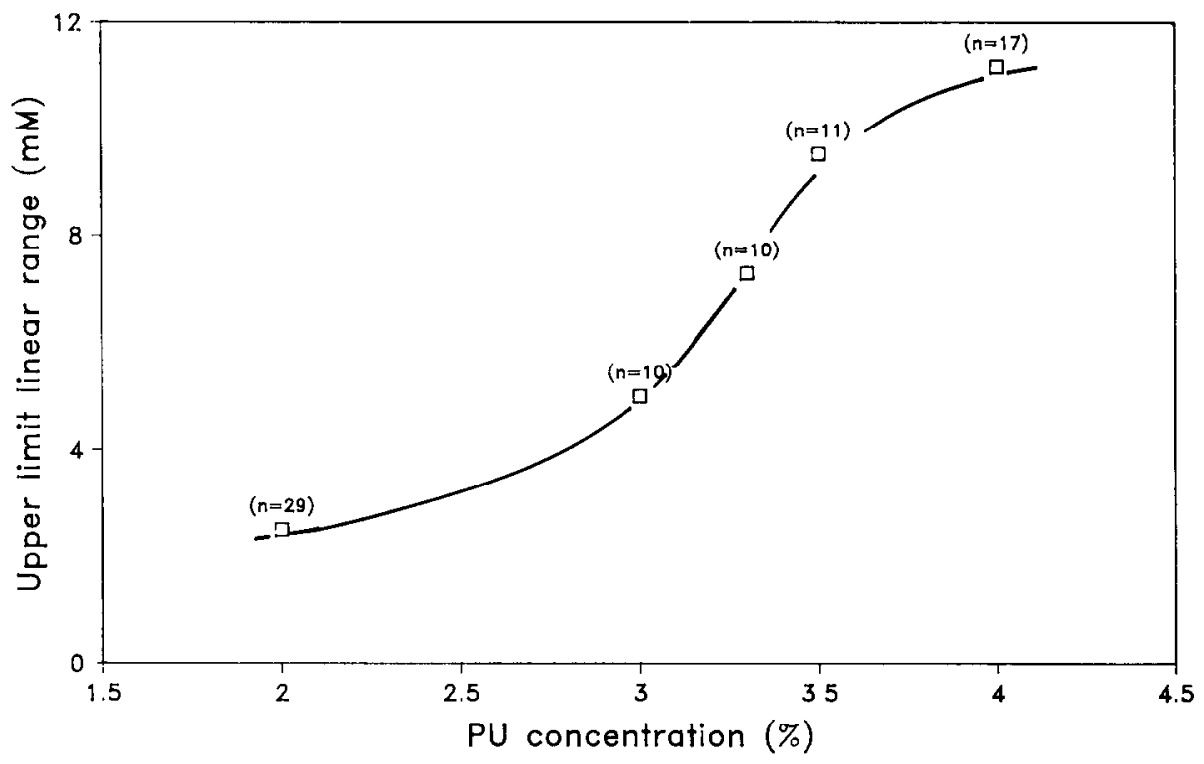

Fig. 2. Variation of sensor upper limit of linear range with $P U$ solution composition used for outer layer deposition on Pt-CA-BSA-PBQ-GOD electrodes. Mean values for sensors prepared by identical procedure.

layer of PU on each Pt-CA-BSA-PBQ-GOD sensor. As shown in Fig. 2, where mean values for 10 to 29 different sensors of identical preparation procedure are presented, the upper limit of the sensor linear range was gradually increased with PU concentration in the polymer solution used for PU deposition. Although results obtained with different needles were considerably scattered, the standard deviation from the mean frequently reaching $70 \%$ ( $n=10$ to 30 ), it appears that $3.5-4 \%$ PU solutions yielded the desired upper extension of linear range. The sensor response to glucose significantly decreased when the PU concentration increased, due no doubt to the formation of a thicker membrane. We found that an optimal outer layer was obtained with a single dip of a $3.5 \%$ polymer solution. A comparison of Protocols 1 and 2 for PU deposition showed no significant difference in final sensor properties.

When a single $3.5 \%$ PU layer was deposited on the Pt-CA-BSA-PBQGOD working electrode, a large percentage of sensors had to be discarded since they yielded either an unacceptably low upper limit of sensor linear range or an unacceptably low response to glucose. It was indeed difficult with this dip-and-dry coating procedure to obtain more than a $30-50 \%$ yield of suitable microsensors. To improve this yield we have tested a multilayer $2 \%$ PU deposition procedure. After each PU layer deposition, sensors were tested for glucose response and, depending upon sensitivity and upper limit 


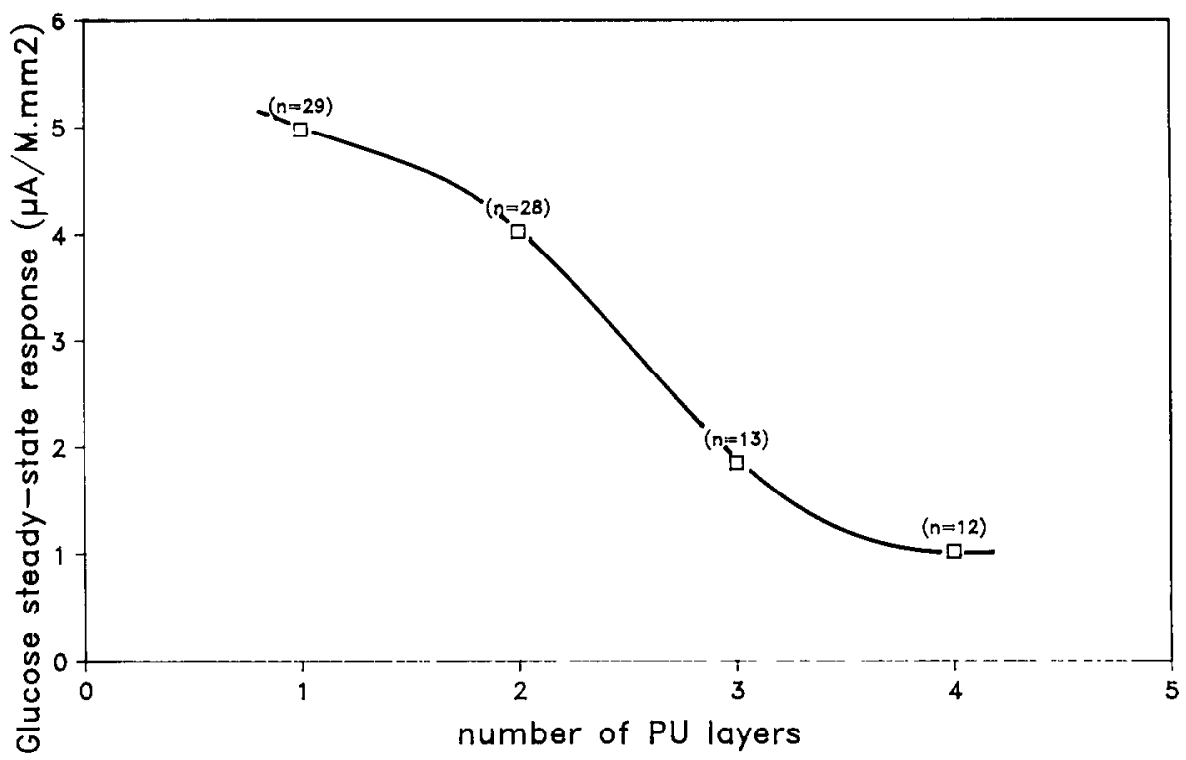

Fig. 3. Effect on sensor response of PU layer thickness. Mean values for sensors prepared by identical procedure. $2 \%$ PU solution used.

of linear range, another $2 \%$ PU layer was deposited. Figure 3 shows that the mean glucose response of sensors, prepared under identical conditions, decreased significantly with the thickness of the PU outer layer. The multistep deposition method made it easier to optimize linear range and response. The main difficulty with this method was the time for preparation and calibration necessary to determine the right number of PU layers for each sensor.

\section{Multilayer permeabilities}

One of the functions of multilayer enzyme membranes covering platinum anodes was to improve electrochemical selectivity of the sensor and discriminate against large or anionic electrochemical interferents. In order to evaluate permselectivity of these layers, we have presented in Table 1 mean values of steady-state responses of sensors to hydrogen peroxide and ascorbate during the successive steps of sensor construction. As these measurements were made under identical stirring conditions and as ascorbate and hydrogen peroxide give almost equal responses on a bare platinum electrode, the ratios allowed the evaluation of membrane permeabilities to small anionic species. It appears from these data that $\mathrm{CA}$ 
layers deposited on $\mathrm{Pt}$ working electrodes yield some selectivity. The mean value of their response ratio reached $0 \cdot 53$. Glucose oxidase immobilization and PU deposition also improved this selectivity, the mean value of their response ratio reaching $0 \cdot 30$ and $0 \cdot 23$, respectively. One should notice that data were quite scattered, demonstrating the difficulties in preparing layers of reproducible thickness, and that the deposited CA layer was somewhat less selective against anions than CA membranes cast on a glass plate and mounted on a rotating membrane assembly for accurate diffusion coefficient determination. Such CA membranes $(24 \mu \mathrm{m}$ thick) yielded apparent diffusion coefficients equal to $(0.38 \pm 0 \cdot 16) \times 10^{-7}$ and $(2.7 \pm 0.3) \times 10^{-7}$ $\mathrm{cm}^{2} \mathrm{~s}-1$ for ascorbate and hydrogen peroxide, respectively, their ratio reaching $0 \cdot 14$ (Apoteker \& Wilson, unpublished results). It should be noted, however, that thicker membranes will discriminate more extensively between peroxide and ascorbate.

\section{In vitro sensor evaluation}

Table 1 presents the needle-type microsensor response to glucose using either one or several PU layers over a Pt-CA-BSA-PBQ-GOD working electrode. When the appropriate PU deposition was realised such sensors yielded suitable properties for subcutaneous in vivo experiments. Sensitivity ranged between 1 and $3 \mu \mathrm{A} \mathrm{M}^{-1} \mathrm{~mm}^{-2}$, upper limit of linear range between 10 and $30 \mathrm{~mm}$ and response time was $30-60 \mathrm{~s}$ and $2-3 \mathrm{~min}$ for transient and steady state, respectively. These data are very similar to those obtained by Velho et al. (1988a) for needle-type glucose microsensors prepared by GOD

TABLE 1

Comparison of Microsensor Response to Glucose, Hydrogen Peroxide and Ascorbate during the Different Steps of the Sensor Construction ${ }^{a}$

Needle-type microsensor responses to

\begin{tabular}{lcccc}
\cline { 2 - 5 } \multicolumn{1}{c}{ Working electrode status } & Glucose & $\begin{array}{c}\text { Hydrogen } \\
\text { peroxide }\end{array}$ & Ascorbate & $\begin{array}{c}\text { Ascorbate: } \\
\mathrm{H}_{2} \mathrm{O}_{2}\end{array}$ \\
\hline $\mathrm{Pt}(n=9)$ & 0 & $7 \cdot 5 \pm 2 \cdot 3$ & $7 \cdot 8 \pm 2 \cdot 1$ & $1 \cdot(07 \pm 0 \cdot 13$ \\
$\mathrm{Pt}-\mathrm{CA}(n=9)$ & 0 & $7 \cdot 6 \pm 2 \cdot 5$ & $4 \cdot 6 \pm 1 \cdot 7$ & $0 \cdot 53 \pm 0 \cdot 21$ \\
$\mathrm{Pt}-\mathrm{CA}-\mathrm{BSA}-\mathrm{PBQ}-\mathrm{GOD}$ & $66 \pm 45$ & $1 \cdot 2 \pm 0 \cdot 4$ & $0 \cdot 3 \pm 0 \cdot 3$ & $0 \cdot 30 \pm 0 \cdot 21$ \\
& $(n=26)$ & $(n=19)$ & $(n=18)$ & $(n=18)$ \\
$\mathrm{Pt}-\mathrm{CA}-\mathrm{nSA}-\mathrm{PBQ}-\mathrm{GOD}+\mathrm{PU}$ & $2 \cdot 2 \pm 1 \cdot 8$ & $0 \cdot 4 \pm 0 \cdot 3$ & $0 \cdot 2 \pm 0 \cdot 1$ & $0 \cdot 23 \pm 0 \cdot 15$ \\
& $(n=16)$ & $(n=14)$ & $(n=13)$ & $(n=13)$ \\
\hline
\end{tabular}

${ }^{a}$ Results expressed as mean \pm standard deviation in $\mu \mathrm{A} \mathrm{M}^{-1} \mathrm{~mm}^{-2}$ for glucose and $\mathrm{mA}{ }^{-1}$ $\mathrm{mm}^{-2}$ for hydrogen peroxide and ascorbate. 
coreticulation with glutaraldehyde (GA) and PU outer layer deposition. The sensitivity of such Pt-CA-GOD-GA + PU needle electrodes was $3.4 \pm 0.69 \mu \mathrm{A} \mathrm{M} \mathrm{Mm}^{-1} \mathrm{~mm}^{-2}$ and their upper limit of linear range was $17 \cdot 1 \pm 0 \cdot 8 \mathrm{mM}(n=14)$ (Velho et al., 1988b).

The microsensor was evaluated for its long-term stability by monitoring the sensor response (enzymatic activity) and the mass of immobilized GOD over an extended period of time. Radiolabelled enzyme was utilized for the latter measurement (Sternberg et al., in press). During the first two weeks of sensor use, no significant release of ${ }^{125}$ I-GOD was detected and the enzymatic response also remained constant. The mass of immobilized GOD on the working electrode was estimated as $1 \cdot 6-3.0 \mu \mathrm{g} \mathrm{mm}^{-2}$. Such microsensors were generally found to be stable over long storage periods at room temperature. For instance, after 53 days a 39\% decrease in sensor response was observed. In some cases the steady-state response to glucose increased significantly after a few weeks. Such behaviour was always accompanied by a decrease in the upper limit of linear range. This change in response was related to the change of PU outer layer structure and properties facilitating more facile glucose transport to the enzyme layer. This observation was supported by the labeling experiments. When an increase in glucose response was observed, the mass of immobilized enzyme was observed to remain constant. Thus while enzyme activity can clearly affect sensor response, the outer membrane may play an even more important role.

\section{In vivo sensor evaluation}

An in vivo method for sensor calibration was used to calculate the apparent subcutaneous glucose level and to evaluate CA-BSA-PBQ-GOD + PU microsensor properties, when implanted in vivo (Velho et al., 1988a). Following insulin injection, the sensor output current decreased to reach a trough, as did the blood glucose concentration (Fig. 4(a)). The pre-insulin and post-insulin injection steady states of the blood glucose level and of the sensor output current made it possible to calculate, by a two-point calibration of the sensor, an in vivo sensitivity coefficient $\left(\mu \mathrm{A} \mathrm{M}^{-1}\right)$. This was determined from the correlation between the decrease in the sensor current and the decrease in blood glucose concentration. To make this calculation, the in vivo background current $\left(I_{0}\right)$, corresponding to extrapolation to zero blood glucose concentration, had also to be determined. These values, determined for each animal and sensor, were used to calculate the apparent subcutaneous glucose level (Fig. 4(a)) during induced hypoglycemia and subsequent hyperglycemia. They demonstrate that, within experimental error, sensor output current correctly followed blood glucose variations. In 25 such experiments performed using $\mathrm{CA}+\mathrm{GOD}-\mathrm{GA}+\mathrm{PU}$ multilayer 


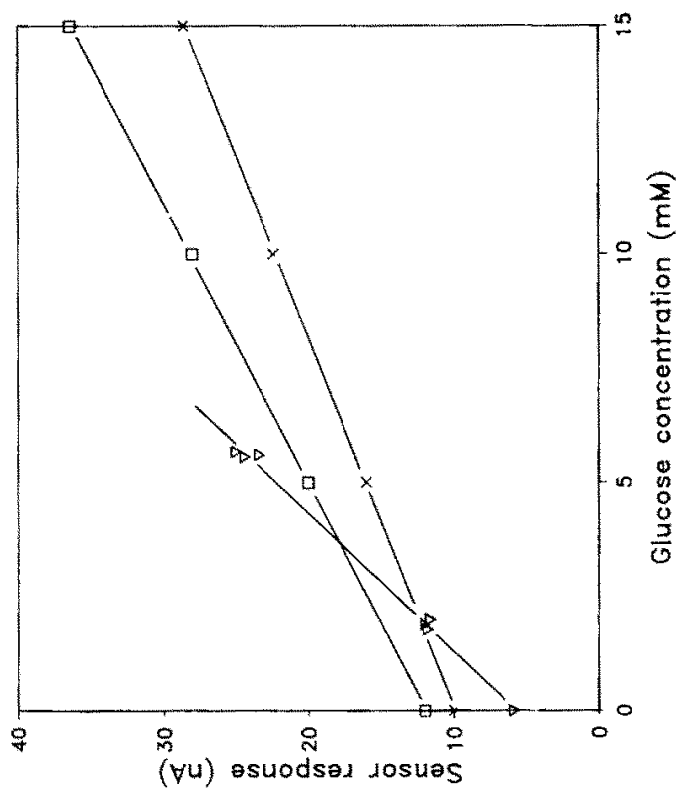

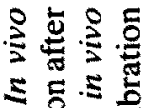

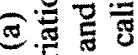

क

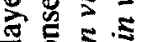

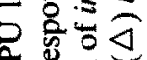

$\circ$ 둥

ते

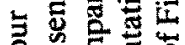

$\underline{2}$

电

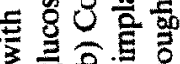

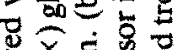

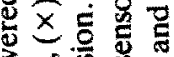

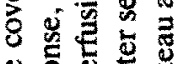

용ㅎㅀ

点范市

\& 8

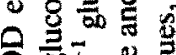

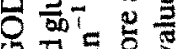

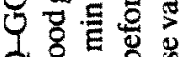

0 용

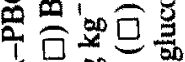

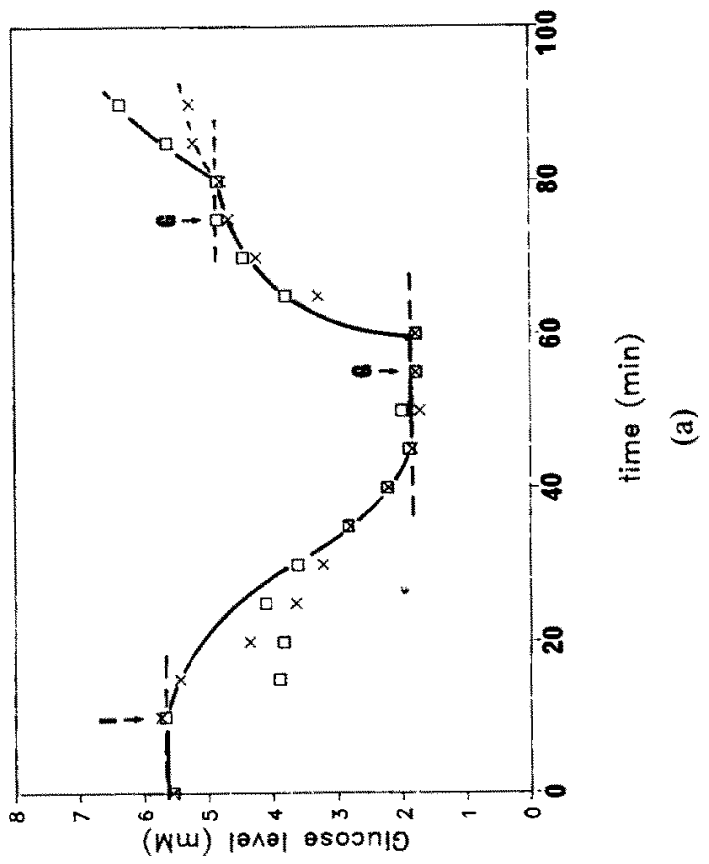

$\ll$ 尔 5

क

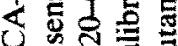

1 苋

ㄴ.

느ㅇㅡㅗ를

政

\% 8

년 융응

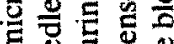

逮罗

$\%$

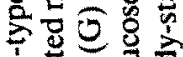

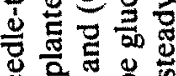

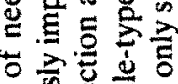

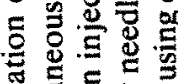

플훙

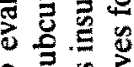

芳苍高

इ5 5

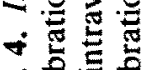

ه: 
sensors, it was found that a $5 \mathrm{~min}$ lag time occurred between the establishment of steady-state subcutaneous glucose levels and a constant blood glucose level (Velho et al., 1988a). When glucose in vitro calibrations were performed before and after such implantation and were compared with in vivo calibration (Fig. 4(b)), four important observations could be made. First, in vitro post- and pre-calibration curves did not differ greatly; the sensitivities varied between 75 and $94 \%$ of the pre-calibration value. Second, the steady-state response time was unchanged. This result is very different from that of some previous experiments using an extracorporal blood shunt where slopes of in vitro post-calibration curves reached only 20-50\% of pre-calibration ones (Thévenot, 1985; Tallagrand et al., 1988). Third, in vivo and in vitro sensitivities were usually significantly different, their ratio varying in our experiments between 0.68 and 2.08 . Finally, in vitro and in vivo background currents $I_{0}$ were significant: they were equivalent to $32-136 \%$ of the response to $5.5 \mathrm{mM}$ normal physiological glucose.

These preliminary results demonstrate the feasibility of subcutaneous implantation of these microsensors for continuous subcutaneous glucose monitoring and their use in indicating blood glucose concentration. They also show that, contrary to previously reported results from groups using either in vitro calibration for in vivo experiments or one-point in vivo calibration procedures (Abel et al., 1983a, b; Reach et al., 1986), it is essential to calibrate in vivo these subcutaneous glucose sensors at two different steady-state blood glucose levels (Velho et al., 1988a).

\section{CONCLUSION}

This report shows that the previously described method for GOD covalent coupling on CA membranes, using BSA and PBQ linkages (Sternberg et al., in press), has been successfully adapted to needle-type microsensor geometry, all layers being deposited by a dip-and-dry technique. Although immobilization was performed on an approximately $1 \mathrm{~mm}^{2}$ platinum surface, these sensors gave output current densities to glucose as large as those obtained with large enzyme membranes, i.e. $66 \pm 45$ and $40-100 \mu \mathrm{A}$ $\mathrm{M}^{-1} \mathrm{~mm}^{-2}$, respectively.

The upper linear range of the glucose calibration curve was extended to 10-30 mM, using one or several PU layers. This step was found to be often irreproducible although performed within a temperature and humidity controlled atmosphere under carefully controlled conditions. The reproducibility of outer layer deposition was definitely the weak link in these microsensor preparation procedures. Although most authors admit that they have 
faced similar difficulties when using the dip-and-dry method, we think that the present development of these needle-type microsensors is limited by this macromolecular chemistry problem and that alternative approaches must be found.

Finally, preliminary in vivo experiments demonstrated that such microsensors could be implanted subcutaneously for $2-6 \mathrm{~h}$ without significant modification of their properties. Experiments are also in progress to improve long-term stability of these sensors by modification of the outer layer in direct contact with the tissue fluid.

\section{ACKNOWLEDGEMENTS}

This work has been supported by 'Caisse Nationale d'Assurance Maladie des Travailleurs Salaries' (Grant CNAMTS-INSERM no. 85.3.54.8.E), French Ministry of Foreign Affairs, National Institutes of Health (US) (Grant DK 30718) and 'Aide aux Jeunes Diabétiques'. G. Velho was supported by grant no. 200131-84 from the Brazilian National Council for Scientific and Technological Development $(\mathrm{CNPq})$. Their financial help is gratefully acknowledged.

\section{REFERENCES}

Abel, P., Fischer, U. \& Freyse, E. J. (1983a). Sandwich membranes for electrochemical glucose measurement in undiluted biological fluid, Life support systems: J. Europ. Soc. Art. Organs, suppl. 1, 94-7.

Abel, P., Fischer, U., Muller, A. \& Freyse, E. J. (1983b). An enzyme electrode for the portable artificial beta cell, Life Support systems: J. Europ. Soc. Art. Organs, suppl. 1, 45-8.

Cherifi, B. (1986). Glucose oxidase immobilization on cellulose diacetate membranes using carbonyldiimidazole activation procedure. Graduate Student research report, D.E.A. de Physico-Chime Biologique et Paramédicale, Université Paris-Val de Marne.

Reach, G., Abel, P. \& Fischer, U. (1986). In vivo evaluation of a glucose sensor in the free-moving Rat, Biosensors, 2, 211-20.

Shichiri, M. \& Kawamori, R. (1983). Glycemic control in pancreatectomized dogs with wearable artificial endocrine pancreas, Diabetologia, 24, 179-84.

Shichiri, M., Kawamori, R., Yamasaki, Y., Hakui, N. \& Abe, H. (1982). Wearable artificial endocrine pancreas with needle-type glucose sensor, Lancet, 2 , 1129-31.

Shichiri, M., Kawamori, R. \& Yamasaki, Y. (1987). Needle-type glucose sensor and its clinical applications, In Biosensors: Fundamentals and Applications, ed. A. P. F. Turner, I. Karube \& G. S. Wilson, Oxford University Press, pp. 409-24.

Sternberg, R., Apoteker, A. \& Thévenot, D. R. (1980). Trace glucose electrode for clinical, food and environmental determinations, In Analytical Chemistry 
Symposia Series, vol. 2: Electrochemistry in Hygiene, Environmental, Clinical and Pharmaceutical Chemistry, ed. W. F. Smyth. Elsevier, Amsterdam. pp. 461-73.

Sternberg, R., Bindra, D. S., Wilson, G. S. \& Thévenot, D. R. (in press). Covalent enzyme coupling on cellulose acetate membranes for glucose sensor development, Anal. Chem.

Tallagrand, T., Sternberg, R., Reach, G. \& Thévenot, D. R. (1988). Evaluation of implantable glucose enzyme-based sensors with extracorporal blood shunt, submitted.

Ternynck, T. \& Avrameas, S. (1976). A new method using parabenzoquinone for coupling antigens and antibodies to marker substances, Ann. Immunol. (Inst. Pasteur), 127C, 197-208.

Thévenot, D. R. (1982). Problems in adapting a glucose oxidase-electrochemical sensor into an implantable glucose sensing device, Diabetes Care, 5(3) 184-9.

Thévenot, D. R. (1985). Analytical bioelectrochemistry, In Electrochemistry in Research and Development, ed. R. Kalvoda \& R. Parsons, Plenum Publishing Corporation, pp. 181-8.

Thévenot, D. R., Coulet, P. R., Sternberg, R. \& Gautheron, D. C. (1978). A highly sensitive glucose electrode using glucose oxidase collagen film, Bioelectrochem. Bioenerg., 5, 548-53.

Thévenot, D. R., Coulet, P. R., Sternberg, R., Laurent, J. \& Gautheron, D. C. (1979). Enzyme collagen membrane for electrochemical determination of glucose traces, Anal. Chem., 51, 96-100.

Thévenot, D. R., Sternberg, R. \& Coulet, P. C. (1982). A glucose electrode using high-stability glucose oxidase collagen membranes, Diabetes Care, 5(3) 203-6.

Velho, G., Reach, G. \& Thévenot, D. R. (1987). The design and development of in vivo glucose sensors for the artificial pancreas, In Biosensors: Fundamentals and Applications, ed. A. P. F. Turner, I. Karube and G. S. Wilson, Oxford University Press, pp. $390-408$.

Velho, G., Froguel, Ph., Thévenot, D. R. \& Reach, G. (1988a). In vivo calibration of a subcutaneous glucose sensor for determination of subcutaneous glucose kinetics, Diabetes, Nutrition and Metabolism: clinical and experimental, 1(3).

Velho, G., Froguel, Ph., Sternberg, R., Thévenot, D. R. \& Reach, G. (1988b). In vitro and in vivo stability of electrode potentials in needle-type sensors: influence of needle material, submitted. 